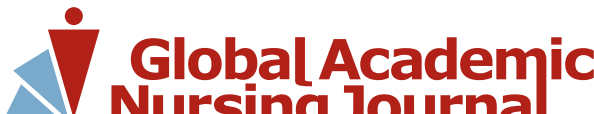 Nursing Journal
}

\section{As implicações emocionais na saúde dos enfermeiros durante a pandemia do SARS-CoV-2}

\author{
Emotional implications for nurses' health during the SARS-CoV-2 pandemic
}

Implicaciones emocionales para la salud de las enfermeras durante la pandemia del SARS-CoV-2

\author{
Geline Nascente Soares Lentz ${ }^{1}$ \\ ORCID: 0000-0002-5134-6314 \\ Euseli de Assis Batista ${ }^{1}$ \\ ORCID: 0000-0002-0107-3565 \\ Juliane Zanon ${ }^{1}$ \\ ORCID: 0000-0002-3211-5203 \\ Letícia Fumagalli da Silva ${ }^{1}$ \\ ORCID: 0000-0001-5742-2528 \\ ${ }^{1}$ Universidade Federal de Santa \\ Catarina. Santa Catarina, Brasil. \\ Como citar este artigo: \\ Lentz GNS, Batista EA, Zanon J, Silva \\ LF. As implicações emocionais na \\ saúde dos enfermeiros durante a \\ pandemia do SARS-CoV-2. Glob Acad \\ Nurs. 2021;2(1):e80. \\ https://dx.doi.org/10.5935/2675- \\ 5602.20200080
}

\section{Autor correspondente:}

Geline Nascente Soares Lentz

E-mail:

geline.nascente@hotmail.com

Editor Chefe: Caroliny dos Santos Guimarães da Fonseca Editor Executivo: Kátia dos Santos Armada de Oliveira

Submissão: $27-11-2020$

Aprovação: 16-12-2020

\section{Resumo}

Considerando-se a situação atual mundial, marcada por importantes crises na saúde pública e, mais recentemente, a pandemia causada pela COVID-19, o presente trabalho buscou juntar informações e pesquisas ligada aos desafios dos profissionais de enfermagem frente a pandemia. As medidas adotadas para lidar com a pandemia, tais como distanciamento social, quarentena e isolamento, são situações extremamente difícil dentro do contexto profissional. Para os profissionais de saúde diretamente ligados ao atendimento de pacientes contaminados com o vírus da COVID-19, existem alguns fatores estressores que podem levar o profissional a extremo desgaste físico e mental. A sobrecarga de trabalho e pressão durante a assistência integral é observada em todos os níveis de atenção ao paciente. É tão necessário cuidar da saúde mental quanto da física dos profissionais linha de frente na pandemia. As características que nos levaram a escolher a enfermagem como profissão são infinitamente importantes neste momento, um período em que o cuidado com o paciente é fator de proteção não só na saúde daquele que busca o atendimento, mas de toda a sociedade. Por fim, serão apresentadas questões relacionadas a parte psicológica do profissional de enfermagem diante da situação de pandemia do novo SARS-CoV-2.

Descritores: Enfermeiro; COVID-19; SARS-CoV-2; Saúde Emocional; Pandemias.

\section{Abstract}

Considering the current global situation, marked by major public health crises and, more recently, the pandemic caused by COVID-19, the present work sought to gather information and research related to the challenges of nursing professionals in the face of the pandemic. The measures adopted to deal with the pandemic, such as social detachment, quarantine, and isolation, are extremely difficult situations within the professional context. For health professionals causally linked to the care of patients infected with the COVID19 virus, there are some stressors that can lead the professional to extreme physical and mental stress. Work overload and pressure during comprehensive care is observed at all levels of patient care. It is just as necessary to take care of the mental health as well as the physical health of the frontline professionals in the pandemic. The characteristics that led us to choose nursing as a profession are infinitely important at this time, a period in which patient care is a protective factor not only in the health of those who seek care, but for the whole of society. Finally, questions related to the psychological part of the nursing professional will be presented in the face of the pandemic situation of the new SARS-CoV- 2 .

Descriptors: Nurse; COVID-19; SARS-CoV-2; Emotional Health; Pandemic.

\section{Resumén}

Considerando la situación mundial actual, marcada por importantes crisis de salud pública y, más recientemente, la pandemia provocada por COVID-19, el presente trabajo buscó recabar información e investigaciones relacionadas con los desafíos de los profesionales de enfermería ante la pandemia. Las medidas adoptadas para hacer frente a la pandemia, como el desapego social, la cuarentena y el aislamiento, son situaciones de extrema dificultad en el contexto profesional. Para los profesionales de la salud directamente vinculados a la atención de pacientes infectados por el virus COVID-19, existen algunos factores estresantes que pueden llevar al profesional a un estrés físico y mental extremo. La sobrecarga de trabajo y la presión durante la atención integral se observan en todos los niveles de atención al paciente. Es igualmente necesario cuidar la salud mental y la salud física de los profesionales de primera línea en la pandemia. Las características que nos llevaron a elegir la enfermería como profesión son infinitamente importantes en este momento, un período en el que el cuidado del paciente es un factor protector no solo de la salud de quienes buscan atención, sino de toda la sociedad. Finalmente, se presentarán cuestiones relacionadas con la parte psicológica del profesional de enfermería ante la situación pandémica del nuevo SARS-CoV-2.

Descriptores: Enfermero; COVID-19; SARS-CoV-2; Salud Emocional; Pandemias. 


\section{Introdução}

Em março de 2020 iniciou-se a pandemia mundial do novo Coronavírus o SARS-CoV-2 - COVID-19, o vírus identificado pela primeira vez na China, cidade de Wuhan em dezembro de 2019, sendo acompanhado pela Organização Mundial de Saúde (OMS). A doença se caracteriza pelo quadro clínico de infecção respiratória graves e infecções assintomáticas em ambos os casos o paciente portador pode ser um agente de contaminação.

Segundo a OMS, a maioria dos casos são de sintomas leves, casos graves e com necessidade de internação hospitalar estão em torno de $15 \%$ a $25 \%$, destes $5 \%$ são compostos por paciente que necessitam de suporte ventilatório.

Na data de 20 de março de 2020, o Brasil declarou conhecimento da transmissão comunitária do agente etiológico da COVID-19, tratando-se de uma doença com características e evolução novas, os profissionais da saúde são os componentes mais expostos a riscos e agravos pela doença. Em 22 de janeiro de 2020, o Brasil, por meio do Centro de Operações de Emergência em Saúde Pública (COECOVID-19) do Ministério da Saúde (MS), coordenado pela Secretaria de Vigilância em Saúde (SVS), iniciou uma série de medidas adotadas para nortear a atuação frente à pandemia em nosso país.

O Brasil adota estratégias seguindo os mesmos protocolos utilizados mundialmente na preparação em reposta à COVID-19, sendo adotado um sistema de classificação de emergência em três níveis: Alerta, Perigo Iminente e Emergência em Saúde Pública; os quais são baseados na avaliação do risco do novo Coronavírus no Brasil e seu impacto para a saúde pública. Englobando recomendações todos os níveis de atenção à saúde de serviços públicos e privados sugerindo a elaboração e implementação de planos de contingência. Estratégias foram geradas para a minimizar a disseminação da doença, dentre elas - destacadas no Ministério da Saúde - estão: a capacitação e atualização constante das equipes de saúde em relação a COVID-19, o reconhecimento de sinais e sintomas da patologia e epidemiologia local relevante com identificação dos grupos de risco. Além de ações de vigilância entre os profissionais de saúde identificando possíveis casos entre o grupo de risco minimizando a transmissão para familiares, paciente e sociedade em geral. Estas estratégias são expandidas as demais equipes atuantes em serviços de saúde como lavanderia, cozinha e limpeza ${ }^{1}$.

O enfrentamento da pandemia é um processo especial das funções da Saúde Pública no que diz respeito à saúde coletiva e no que se trata da saúde dos profissionais da linha de frente nos serviços de saúde. As diretrizes da OMS para profissionais da saúde em atendimento aos pacientes em geral são: o uso de máscara descartável em qualquer momento do atendimento; em atendimento aos pacientes suspeitos/confirmados, o profissional deve utilizar máscara, óculos de proteção ou face shield, roupas/aventais impermeáveis e luvas de procedimento, em caso de realização de procedimentos que possam ser geradores de esta indicado o uso de máscaras PFF ou N95 (ou qualquer outra máscara que haja contenção de aerossóis), toucas, sapatos fechados e protetores de sapato; associados à higiene das mãos e uso de álcool em gel quando a lavagem das mãos não for possível.

As medidas de distanciamento social mostraram-se a estratégia mais eficaz na minimização da proliferação do vírus SARS-CoV-2, porém para o profissional da saúde esta medida torna-se prática impossível diante de seu papel na assistência direta ao paciente com suspeita ou portador confirmado da COVID-19. Para estes profissionais, a rotina do cuidado se torna extremamente desgastante e, frequentemente associada a condições não ideais de assistência, além da alta carga viral a qual estão expostos, levando ao aumento do risco de infecção em sua atividade profissional ${ }^{2}$.

Os profissionais atuantes na linha de frente da pandemia do novo Coronavírus - SARS-CoV-2 compartilham do medo em geral da população de contrair a patologia, e até mesmo morrer, porém a situação de estresse em que se encontram é agravada pelo medo constante de ser agente infectante de pessoas próximas, colegas de trabalho, não conseguir salvar seus pacientes e até mesmo infectar pacientes durante sua assistência. Corroborando com esta situação, o fato de que os profissionais por inúmeras vezes exercem suas atividades sem a disponibilização de equipamentos de proteção individual adequados, com número de profissionais abaixo do que é preconizado em lei, dificuldades em seguir seu fluxo de trabalho corretamente ${ }^{3}$.

A pandemia da COVID-19 tem mostrado números alarmantes de pessoas infectadas e óbitos, estes associados com a velocidade de transmissão impactam diretamente na vida da população mundial. De acordo com o relatório da OMS, até a data de 3 de junho de 2020 foram notificados 6.287.771 casos confirmados e 379.941 óbitos, tendo como principais continentes afetados Europeu e Americano².

Em abril de 2020, a pandemia do vírus SARS-CoV-2 já era considerada a síndrome respiratória mais severa desde a Gripe Espanhola datada do ano de 1918, a preocupação com a mais nova síndrome gripal nomeada de COVID-19 passa pelos problemas relacionados a um possível colapso nos sistemas de saúde, já que nem em características físicas ou de recrutamento de pessoal as instituições de saúde estavam preparadas para o aumento tão expressivo da demanda de pacientes ${ }^{3}$.

A OMS, no ano de 2007, já tinha como assunto de debate a preparação dos países para enfrentar crises e desastres inesperados. A orientação naquele momento era que os países criassem modelos para atendimento nesses agravos inesperados, observando a crise na saúde pública foi evidenciada a importância da preocupação primordial com os aspectos mentais equiparando-os com cuidados de atenção primária ${ }^{4}$.

Em geral, pandemias são associadas a um grande número de mortes, fator este que na pandemia pela COVID19 pode ser associado ao impacto psicológico causado na sociedade, não só pela convivência com o novo microrganismo, mas pelas medias necessárias de isolamento e afastamento social. Sintomas como ansiedade, depressão e estresse podem ser observados durante este período. A 
crise pandêmica pode ser sentida nos aspectos epidemiológico e psicológico ${ }^{5}$.

Além do pânico generalizado que uma pandemia pode causar na sociedade, ainda mais quando não se tem o conhecimento ou ele está sendo adquirido sobre aquele patógeno. A produção de vacinas e fármacos encontra-se em processo de estudos, sendo necessário como medida efetiva o isolamento social, dinâmica essa que mudou o cotidiano, relações, trabalho e interações sociais dos indivíduos mundialmente. A necessidade do isolamento social aumenta os sentimentos de solidão, tédio, desamparo, tristeza e as reações como distúrbios de sono, apetite e conflitos interpessoais mostram-se aumentados durante a pandemia $^{6}$.

A enfermagem constitui o maior número de profissionais dentro das instituições hospitalares, a profissão associa conhecimento científico e técnico na assistência direta ao paciente. O cotidiano profissional da equipe já é gerador de situações de extremo estresse, ansiedade e medo. Sintomas característicos de sofrimento psicológico que podem ser associados com a prática profissional, sobrecarga de trabalho, desgaste, suporte social e as relações dos profissionais com paciente, família e equipe. 0 profissional atuante na pandemia deparou-se com o atendimento ao paciente potencialmente grave com necessário apoio da equipe intensivamente e necessitando de diversos protocolos para garantir seu tratamento, necessidade de uso de equipamentos de proteção individual durante toda sua jornada, o medo de infecção, o isolamento social e, principalmente, familiar. Todos estes fatores são aliados no processo de sofrimento mental do profissional de enfermagem, aumentando os níveis de ansiedade em todas as áreas onde os pacientes portadores de COVID-19 estão internados ${ }^{7}$.

O impacto psicológico da pandemia levou ao aumento de Transtornos Mentais Comuns (TMC), com destaque a fadiga, estresse, agressividade, pânico, dentro outros, incluindo os transtornos pós-trauma. Além disto, profissionais estão suscetíveis a risco de violência social e suicídio ${ }^{8}$.

Estudos trazem os principais fatores de risco de infecção pela COVID-19 durante o atendimento do profissional de saúde: alta exposição ocupacional ao vírus; medo de se infectar e transmitir para colegas da equipe e familiares; isolamento social e dificuldade de contato com a rede de apoio, longas jornadas de trabalho durante a pandemia; trabalhar diretamente no processo de cuidado e tratamento ao paciente com COVID-19; fadiga física; falta de equipamento de proteção individual; ausência de diretrizes rigorosas de controle de infecções na instituição; sentimento de imponência em relação à cura de paciente graves; falta de acesso às informações sobre a COVID-19; falta de reconhecimento profissional pelos superiores e morte de pacientes. Ressalta ainda que profissionais que atuam nos setores de emergência, unidade de terapia intensiva e isolamento estão mais propensos a ficarem abalados psicologicamente devido à alta carga viral do paciente e alta demanda de trabalho ${ }^{9}$.
Devido ao novo Coronavírus apresentar sintomas semelhantes a um resfriado, o profissional que apresenta estes sintomas entra em um dilema de afastamento de suas atividades para preservar colegas de trabalho e pacientes e, consequentemente, necessita de isolamento social, afastando-se do seio familiar.

O profissional de enfermagem é o apoio psicológico o qual o paciente se apega durante a necessidade de atenção em saúde, porém no momento da pandemia este profissional não consegue realizar esta tarefa de forma qualificada devido a este abalo em sua saúde mental. A OMS e as entidades de classe em enfermagem percebendo essa demanda psicológica advinda dos profissionais da saúde já organizam ações de cuidado psicológico para os profissionais ${ }^{7,9}$.

No cenário atual de pandemia mundial, as ações de educação continuada com foco em proteções individuais e coletivas dos profissionais da linha de frente se fazem extremamente necessárias, auxiliando a manutenção da segurança e agindo como ação que visa minimizar os sentimentos de ansiedade e medo. Outras ações, como apoio psicológico via telefone ou presencial, se fazem primordiais para ouvir as angústias e medos dos profissionais durante estes momentos em que o profissional pode ter necessidade de exteriorizar suas demandas, fazendo isto, o profissional pode sentir-se apoiado e mais confiante.

O Conselho Federal de Enfermagem também sugeriu como medida de enfrentamento a pandemia a mudança de profissionais acima dos 60 anos, gestantes e portadores de doenças crônicas (grupo de risco) para outros setores onde não só o risco biológico é minimizado, mas também situações de estresse emocional se tornam menos constantes. É primordial que as instituições criem setores de apoio psicológico ao profissional que está exercendo suas funções em meio a pandemia, subsidiando a este profissional a segurança durante a prática profissional, mas também assegurando a sua saúde mental ${ }^{9}$.

Este estudo tem como objetivo descrever as implicações psicológicas enfrentadas por enfermeiras atuantes como linha de frente na pandemia de COVID-19 no âmbito da saúde pública, emergência pediátrica e atendimento pré-hospitalar.

\section{Metodologia}

Foi baseado em vivências profissionais das autoras que atuaram como linha de frente na pandemia de COVID19 durante os meses de abril a novembro de 2020 na cidade de Criciúma no serviço de pré-hospitalar e atenção básica, na cidade de Florianópolis no contexto de emergência pediátrica e cidade de Videira também no âmbito da atenção básica; ambas as cidades localizas no Estado de Santa Catarina - Brasil.

\section{Relato da Experiência}

Este estudo tem como objetivo alertar sobre a impacto psicológico do vírus da COVID-19 entre os profissionais de enfermagem que atuam na linha frente da pandemia. Com nossa vivência profissional mista frente à pandemia, fomos capazes de encontrar este ponto em 
comum entre o atendimento na atenção básica de saúde, setor de emergência pediátrica em hospital de grande porte e no atendimento pré-hospitalar em unidade avançada. $\mathrm{Na}$ construção deste trabalho observamos que algumas vivências foram compartilhadas como a incerteza perante as condutas no início da pandemia, a necessidade de informações e orientações quando o vírus se instalou em nosso estado, a necessidade do uso correto e contínuo dos equipamentos de proteção individual e o sofrimento psicológico com o medo da infecção e possível infecção de nossos familiares.

A demanda de todas as equipes foram aumentadas exponencialmente e, no caso da atenção básica, houve a necessidade de realocar profissionais para os novos centros de triagem destinados especificamente aos pacientes sintomáticos da COVID-19, gerando um novo desafio na vida profissional deste enfermeiro, uma mudança não só em seu ambiente de trabalho escolhido inicialmente, mas na necessidade de envolver-se em uma nova equipe estimulando e orientando sobre cuidados que não faziam parte de sua rotina até o momento que antecedeu a pandemia.

Ainda no âmbito da atenção básica foi criado um departamento denominado sala de situação em saúde onde o enfermeiro é o líder na busca da resolução de questões pertinentes ao atendimento dos pacientes em sua unidade, questões estas que são levadas até a vigilância epidemiológica de seu município e, posteriormente, respondidas via memorando pelos superiores, criando um vínculo sólido e resolutivo às questões diárias frente à COVID-19. Em sua estrutura física, as unidades de atenção básica foram afetas pela pandemia, os agendamentos somente via telefone, visitas domiciliares realizadas em casos especiais, ambulatórios e consultórios de enfermagem recentemente inaugurados foram fechados, necessidade de redução do número de usuários dentro da unidade e infinitas outras ações pontuais que houve a necessidade de serem revistas no cenário atual.

Setores de emergência pediátrica em tempos sem pandemia já são extremamente difíceis para a enfermagem. A demanda do paciente deve ser atendida assim como o anseio de um familiar que está ali como acompanhante, as técnicas devem ser executadas de maneira rápida e resolutiva e o estresse de lidar com o paciente pediátrico é diário. A pandemia da COVID-19 gerou neste setor um novo gatilho de pânico pela possível infecção que no início da pandemia chegou a níveis altos, gerando abstinência de diversos funcionários daquele setor e, em consequência, uma sobrecarga de trabalho. O setor de emergência, por ser um setor dinâmico onde diversas tarefas são executadas na sequência, se torna fisicamente cansativo, com a pandemia o uso de equipamentos de proteção individual tornou essa rotina mais desgastante, pois diversos destes equipamentos levam a lesões físicas, como as máscaras PFF/N95. O profissional deste setor tem a necessidade de permanecer portando os equipamentos durante toda sua jornada de trabalho, pois não sabe qual o perfil do paciente que receberá.
O serviço de atenção pré-hospitalar vive sempre dias incertos, nenhum dia de trabalho é como o outro e nunca sabemos o que esperar para o próximo atendimento. Esta expectativa aumentou após a pandemia, pois nosso trabalho tem a necessidade de adentrar a todo tipo de lugar, as equipes mudaram seu olhar durante o atendimento ao paciente tornando-se muito mais criteriosa e crítica ao uso de equipamentos de proteção individual. $O$ atendimento do paciente inicia no serviço de regulação médica, ali já acontece o primeiro contato do solicitante ao médico regulador que deve solicitar se existem ou não sinais de síndrome gripal, caso haja suspeita o médico regulador no momento do acionamento da equipe já comunica a necessidade de paramentação completa (em casos sem suspeita é realizado o atendimento com precaução padrão e máscaras PFF/N95) e a necessidade de minimizar os materiais que irão até o paciente com a preocupação de menos materiais possivelmente contaminados após a ocorrência.

As equipes ainda realizam as transferências entre hospitais do paciente confirmado com COVID-19, e ao término desta transferência devem higienizar materiais utilizados e, quando não estiverem presentes as higienizadoras nas bases operacionais (após 18:00 horas), a própria equipe realiza a desinfecção da viatura. Os próprios enfermeiros do serviço da unidade avançada criaram um método para desparamentação segura de toda equipe, esta etapa é realizada em conjunto onde cada um consegue observar o colega e apontar o possível momento de contaminação na desparamentação, momento este que julgam essencial para manter a saúde da equipe.

Observamos que os gestores de nosso serviços de saúde ofertaram de maneira correta as capacitações que cada área de cuidado necessitava, seja de maneira in loco, digital, ou através de documentos estas capacitações foram ofertadas, aqui observamos a dificuldade que é para o gestor adaptar-se a este momento, pois nossa profissão é extremamente prática e por diversas vezes necessita de encontros presenciais para demostrar alguma técnica, não sendo possível neste momento e adaptando a tecnologia a favor da saúde.

$O$ ponto em comum a todas as autoras foi o desgaste do profissional de enfermagem durante a pandemia, como atuantes da linha de frente sentimos o quanto nosso psicológico foi afetado, nosso principal fator de estresse é o medo de infectar nossas famílias por conta de nossas atividades, como todos os profissionais, necessitamos manter o afastamento e ficar em isolamento de nossas famílias o que nos gerou sentimentos como frustação e tristeza.

A perda de colegas da enfermagem nos gera medo e ansiedade, ficamos pensando por muitas vezes onde erramos, e quais pontos necessitamos melhorar. $\mathrm{O}$ aumento da demanda de trabalho e o cancelamento de férias aumentaram a exaustão física. Verificamos ainda o preconceito pela nossa profissão ao divulgar em qualquer local que seja necessário, notamos que as pessoas nos olham com olhares julgadores e nos diferem como se fossemos a única fonte infectante da pandemia. 
Observamos em nossos locais de trabalho ações das gerências para minimizar os impactos psicológicos e auxiliar no sofrimento do profissional de enfermagem, mas ainda verificamos que não são ações obrigatórias e sem cunho nacional, obtendo pouca aderência da equipe pelos estigmas que ainda existem perante os sofrimentos psicológicos.

\section{Conclusão}

Diante do cenário pandêmico atual, observamos a enfermagem como uma das categorias com maior impacto psicológico dentre os profissionais de saúde devido ao alto tempo despendido no cuidado ao paciente e as altas jornadas de trabalho associadas ao medo de infecção pela COVID-19. É indispensável pensarmos não somente na saúde física dos enfermeiros atuantes na linha de frente, como nos impactos psicológicos que o enfrentamento desta pandemia pode causar.
Em nosso relato fica claro que, apesar das diferentes áreas de atuação, os impactos gerados como os problemas estruturais e de equipe são os mesmos enfrentados pelos enfermeiros.

Como enfermeiros, devemos ser além de líderes, devemos ser modelos de saúde à nossa equipe que se encontra tão fragilizada neste momento, mantendo nossa saúde mental em dia, buscando apoio sempre que necessário e fortalecer esta necessidade com gestores e toda a equipe de saúde atuante no cuidado direto ao paciente. Mantendo e estimulando sua equipe com a certeza de que dias melhores virão para os profissionais de enfermagem e os aprendizados dessa pandemia serão norteadores e legado para a próxima geração da enfermagem brasileira.

\section{Referências}

1. Agência Nacional de Vigilância Sanitária (BR). Nota Técnica. Orientações para o serviço de saúde: medidas de prevenção e controle que devem ser adotadas durante a assistência aos casos suspeitos ou confirmados de infecção pelo novo coronavirus. portal.anvisa.gov. [Internet] 16 de Setembro de 2020. http://portal.anvisa.gov.br/documents/33852/271858/Nota+T\%C3\%A9cnica+n+ 04-2020+GVIMSGGTES-ANVISA/ab598660-3de4-4f14-8e6f-b9341c196b28.

2. Teixeira CS, et al. A saúde dos profissionais de saúde no enfrentamento da pandemia de COVID-19. Revista Ciência e saúde Coletiva. 2020;25(9). https://doi.org/10.1590/1413-81232020259.19562020

3. Schmidt B, et al. Saúde mental e interveções psicológicas diante do novo coronavirus. Estudos piscol. 2020;37. https://doi.org/10.1590/1982-0275202037e200063

4. Faro A, et al. COVID-19 e saúde mental: a emergência do cuidado. Estudos psicol. 2020;37. https://doi.org/10.1590/1982$0275202037 \mathrm{e} 200074$

5. Crepaldi MA, et al. Terminalidade, morte e luto na pandemia de COVID-19: demandas psicológicas e emergentes e implicações práticas. Estudos de psicol. 2020;37. https://doi.org/10.1590/1982-0275202037e200090

6. Humerez DC, et al. Saúde mental dos profissionais de enfermagem do Brasil no contexto da pandemia COVID-19. Ação do Conselho Federal de Enfermagem. Cogitare Enferm. 2020;25:e74115. http://dx.doi.org/10.5380/ce.v25i0.74115

7. Dal'Bosco EB, et al. A saúde mental da enfermagem no enfrentamento da COVID-19 em um Hospital Universitário Regional. Rev bras enferm. 2020;73(supl.2). https://doi.org/10.1590/0034-7167-2020-0434

8. Cruz RM, et al. Emergência e impactona saúde do trabalho. Rev Psicol. 2020;20(2). http://dx.doi.org/10.17652/rpot/2020.2.editorial

9. Santos WA, et al. O impacto da pandemia da COVID-19 na saúde mental dos profissionais de saúde: revisão integrativa. RSD. 2020;9(8). http://dx.doi.org/10.33448/rsd-v9i8.5470. 